\title{
CORRIGENDUM
}

\section{Global CNS gene delivery and evasion of anti-AAV-neutralizing antibodies by intrathecal AAV administration in non-human primates}

SJ Gray, S Nagabhushan Kalburgi, TJ McCown and R Jude Samulski

Gene Therapy (2013) 20, 465; doi:10.1038/gt.2013.11

Correction to: Gene Therapy (2013) 20, 450-459; doi:10.1038/ gt.2012.101; published online 10 January 2013

Since the online publication of this article, the following errors have been identified.

In Figure 2b, the black bars indicate AAV9 (101-IC and 102-IC) and the white bars indicate AAV2.5 (103-IC and 104-IC). Figure 2a was labeled correctly. In Figure 5, panels F and G were mislabeled: panel $F$ should be spleen and panel $G$ should be liver. Similarly, in Supplementary Figure 4, panel E should be spleen and panel F should be liver.

The corrected article appears in this issue, and the html and PDF versions online have also been amended.

The authors would like to apologize for these errors. 